\title{
Effect of Gender on the Radiation Sensitivity of Murine Blood Cells
}

\author{
Paul C. Billings ${ }^{1}$, Ana L. Romero-Weaver ${ }^{1}$, and Ann R. Kennedy ${ }^{1}$ \\ ${ }^{1}$ Department of Radiation Oncology, University of Pennsylvania, Perelman School of Medicine, Philadelphia, PA \\ 19104
}

\begin{abstract}
Space travel beyond the Earth's protective magnetosphere risks exposing astronauts to ionizing radiation, such as that generated during a solar particle event (SPE). Ionizing radiation has well documented effects on blood cells and it is generally assumed that these effects contribute to the hematopoietic syndrome (HS), observed in animals and humans, following exposure to total body irradiation (TBI). The purpose of the current study was to assess the role of gender on the effects of gamma radiation on blood cells. $\mathrm{C} 3 \mathrm{H} / \mathrm{HeN}$ mice were irradiated with a ${ }^{137} \mathrm{Cs}$ gamma source. Radiation had similar effects on white blood cells (WBCs), lymphocytes, and granulocytes in male and female $\mathrm{C} 3 \mathrm{H} / \mathrm{HeN}$ mice, while red blood cell (RBC) counts and hematocrit values remained stable following radiation exposure. Non-irradiated male mice had 13\% higher platelet counts, compared with their female counterparts, and showed enhanced recovery of platelets on day 16 following radiation exposure.
\end{abstract}

Key words: Hematopoietic Syndrome; Red Blood Cell; Solar Particle Event; Total Body Irradiation; White Blood Cell

Correspondence to: Ann R. Kennedy

University of Pennsylvania

Perelman School of Medicine

Department of Radiation Oncology

3400 Civic Center Boulevard

Philadelphia, PA 19104

Telephone: 215-898-0079

E-mail: akennedy@mail.med.upenn.edu
Hence, gender differences influence the response of platelets to TBI exposure.

\section{INTRODUCTION}

Exploration class missions are being planned by NASA, which will involve space travel over periods of months to years. Space travel beyond the Earth's protective magnetosphere exposes astronauts to risks from acute and chronic exposure, to ionizing radiation. Of particular concern is radiation generated during a SPE $(\mathrm{Hu}$ et al., 2009). In a SPE, magnetic disturbances in specific regions of the Sun result in the release of intense bursts of ionizing radiation, composed mainly of relatively low energy protons with most in the range of $50-100 \mathrm{MeV}$, but which can also include a minor contribution from helium ions $(\sim 10 \%)$ and heavy ions and electrons $(\sim 1 \%)$ (Wilson et al., 1977; Smart and Shea, 2003).

SPE radiation represents a serious concern for astronauts spending extended time in the space environment (Kerr, 2013; Zeitlin et al., 2013). SPE radiation doses can be particularly high during extravehicular activities (EVAs); for instance, it has been estimated that the August 1972 SPE could have delivered doses of approximately 2.69 Gy and 0.46 Gy to skin and blood forming organs (BFO) in a spacecraft, and 32 Gy and 1.38 Gy to skin and BFO, respectively, during extra-vehicular activity (EVA) (Hu et al., 2009). It has been estimated that SPE dose rates range from 0 to $50 \mathrm{cGy} /$ hour, and the largest internal dose is expected to be $2 \mathrm{~Gy}$ ( $\mathrm{Hu}$ et al., 2009; Townsend, 2005). SPEs usually last for no more than several hours, although some SPEs can 
continue for several days. Unfortunately, SPEs are difficult to forecast in advance. This makes the goal of accurately predicting the biological effects for SPE exposed astronauts even more critical so that potential adverse events can be anticipated and strategies for mitigation can be developed.

Exposure to ionizing radiation is known to have lethal effects in blood cells (Dainiak, 2002). Prior studies in mice demonstrated that following exposure to SPE radiation, lymphocytes, a type of WBC, show the most immediate response to ionizing radiation by exhibiting a dramatic drop 24 hours following radiation exposure, and then recovery occurs. In contrast, platelets decline more gradually, over a longer time period (Maks et al., 2011; Romero-Weaver et al., 2013a). Studies examining the effects of ionizing radiation on blood cells have used either male or female mice, exclusively. The purpose of the current study was to determine the role of gender in radiation-induced hematopoietic cell killing of blood cells by directly comparing the radiation response in male and female mice.

We have performed many previous experiments in which the effects of simulated SPE-like proton radiation have been compared to those from standard reference radiations, such as gamma radiation from ${ }^{60} \mathrm{Co}$ (Maks et al., 2011) or ${ }^{137} \mathrm{Cs}$ (Romero-Weaver et al., 2013a; RomeroWeaver et al., 2013b), with particular focus on the energy and dose-rates of the protons. Most of our experiments have utilized homogeneous doses of SPE-like protons (of energies ranging from 50-70 $\mathrm{MeV}$ ) and dose rates of high dose-rates (50 cGy/minute) or SPE-like dose-rates (e.g., 50 or 17 cGy/hour). Previously, we determined that over the dose range of 0.5-2 Gy, the dose-response relationships for the numbers of peripheral blood cells of various types following the exposure of mice to SPE-like proton and gamma radiation were approximately the same, with the doseresponse curves being nearly identical, and that the RBE of low energy SPE-like protons was not significantly different from one when gamma-rays were used as the reference radiation (Maks et al., 2011; Romero-Weaver et al., 2013a; RomeroWeaver et al., 2013b).

For the comparison of dose-rate effects, some studies showed a very small sparing effect $(11.2 \%)$ for low dose-rate, SPE-like proton radiation compared to high dose-rate SPE-like proton radiation (Maks et al., 2011); while the results of other experiments involving SPE-like proton radiation at the SPE low dose-rates of 50 and $17 \mathrm{cG} /$ hour indicated that the differences between the results, following mouse exposure to low dose-rate and high dose-rate radiation for peripheral hematopoietic cell counts, were not statistically significant (Sanzari et al., 2014). It has been concluded from these studies in mice that the dose-rate effects of low dose-rate SPE, or gamma radiation in peripheral hematopoietic cell counts, are not of biological significance. Thus, the results of our studies have suggested that the effects of gamma radiation in mice can approximate the results that would be expected from the use of SPE-like proton radiation in mice. The dose of 2 Gy was chosen for the studies described here, as that is the highest internal dose expected for astronaut exposure to SPE radiation.

\section{MATERIALS AND METHODS}

Male and female $\mathrm{C} 3 \mathrm{H} / \mathrm{HeN}$ mice were obtained from Charles River (Wilmington, MA). Twelve week old animals were housed in groups of five mice per cage, with ad libitum access to food and water. Mice were irradiated with a ${ }^{137} \mathrm{Cs}$ gamma source at a dose rate of $0.4 \mathrm{~Gy} / \mathrm{min}$. At defined time points post-irradiation, animals were euthanized by $\mathrm{CO}_{2}$ inhalation and blood was obtained via cardiac puncture as described (Romero-Weaver and Kennedy, 2012). Approximately $300 \mu 1$ of blood was placed in BD Microtainer tubes containing EDTA (BD, Franklin Lakes, NJ). Complete blood cell analysis $(\mathrm{CBC})$, along with differential counts was performed by Antech Diagnostics. At least five animals were used for each time point. All procedures for animal care and experimental treatments were approved by the Institutional Animal Care and Use Committee (IACUC) of the University of Pennsylvania. Results obtained were analyzed using the Students T-test.

\section{RESULTS AND DISCUSSION}

Two independent experiments were performed to determine whether gender differences in blood cell counts occurred in irradiated mice. $\mathrm{C} 3 \mathrm{H} / \mathrm{HeN}$ mice were utilized, as this strain is very radio-sensitive and has been 
widely used to study the biological effects of ionizing radiation (Gaberman et al., 2013; Ghosh et al., 2012). The results indicated that similar data trends occurred in each independent experiment; thus, the results presented are pooled results, obtained from two independent experiments. We first compared blood cell counts in unirradiated, control animals. There was little difference in the levels of total WBCs, neutrophils, lymphocytes, or granulocytes (neutrophils+basophils+eosinophils) in blood obtained from male or female mice. Both male and female mice had similar numbers of RBCs, as well as nearly identical levels of hemoglobin and hematocrits (Table 1). In contrast, we observed that male mice had platelet counts that were $13 \%$ higher than those of female mice.

Table 1. Blood cell counts in non-irradiated male and female $\mathrm{C} 3 \mathrm{H} / \mathrm{HeN}$ mice. ${ }^{1}$

\begin{tabular}{|c|c|c|c|c|c|}
\hline \multirow{2}{*}{ Cells \& Other Parameters } & \multicolumn{2}{|c|}{ Male } & \multicolumn{2}{|c|}{ Female } & \multirow{2}{*}{ P-value ${ }^{4}$} \\
\hline & $\mathbf{A V E}^{2}$ & $\mathbf{n}^{3}$ & $\mathbf{A V E} \mathbf{E}^{2}$ & $\mathbf{n}^{3}$ & \\
\hline WBCs $\left(\times 10^{3} / \mu 1\right)$ & $7.6 \pm 2.5$ & 42 & $7.4 \pm 2.1$ & 41 & 0.68 \\
\hline RBCs $\left(\times 10^{6} / \mu 1\right)$ & $7.9 \pm 0.5$ & 41 & $7.9 \pm 0.6$ & 41 & 0.87 \\
\hline Hemoglobin $(\mathrm{g} / \mathrm{dl})$ & $13.5 \pm 0.6$ & 41 & $13.7 \pm 0.5$ & 41 & 0.2 \\
\hline Hematocrit (\%) & $44.2 \pm 2.4$ & 41 & $44 \pm 1.9$ & 41 & 0.64 \\
\hline 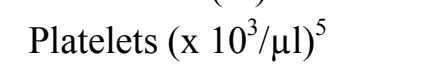 & $1114 \pm 196$ & 41 & $966 \pm 202$ & 41 & 0.0012 \\
\hline Neutrophils $(/ \mu 1)$ & $1848 \pm 1416$ & 41 & $1493 \pm 544$ & 42 & 0.13 \\
\hline Lymphocytes $(/ \mu \mathrm{l})$ & $5291 \pm 1569$ & 42 & $5561 \pm 1655$ & 42 & 0.44 \\
\hline Monocytes $(/ \mu \mathrm{l})$ & $154 \pm 127$ & 42 & $145 \pm 164$ & 42 & 0.76 \\
\hline Eosinophils $(/ \mu \mathrm{l})$ & $127 \pm 85$ & 42 & $130 \pm 87$ & 42 & 0.86 \\
\hline Basophils $(/ \mu 1)$ & $53 \pm 71$ & 42 & $55 \pm 68$ & 42 & 0.89 \\
\hline Granulocytes $(/ \mu 1)^{6}$ & $2029 \pm 1443$ & 41 & $1678 \pm 594$ & 42 & 0.15 \\
\hline
\end{tabular}

1. Blood cell counts obtained from all control (non-irradiated) animals used in these studies.

2. Ave: Mean cell count \pm Standard deviation (SD)

3. n: number of animals

4. P-value- Statistical analysis: Students $T$ test, male vs female

5. Males had $13 \%$ higher platelet counts than female mice $(p=0.0012)$

6. Granulocytes: neutrophils + basophils + eosinophils

We next investigated the effects of gamma irradiation on blood cell counts in male and female mice. For these studies, mice were exposed to $0,0.5,1$, and 2 Gy gamma radiation and blood samples were obtained at $1,4,11$, and 16 days post-irradiation. Previously, we determined that the effects of SPE radiation and gamma radiation on peripheral blood cell counts in mice were comparable, as described in the Introduction. Therefore, we feel that the results obtained in the current study using gamma radiation would be approximately the same as those expected for SPE-like protons.
In general, gamma radiation had similar effects on blood cell populations in both male and female mice at all doses and time points analyzed. As expected, these effects were proportional to dose, i.e. the most pronounced effects were observed at 1- 2 Gy, while at 0.5 Gy the differences between the peripheral hematopoietic cell counts observed for male and female mice were not statistically significant. Hence, the data reported are results obtained at radiation doses of 1 and 2 Gy. The levels of RBCs, hematocrit, and hemoglobin remained within $10 \%$ of those from control, unirradiated mice throughout the course of the observation period (data not shown). At a 
dose of 2 Gy, WBCs and lymphocytes exhibited a significant initial decline of about $60-70 \%$ at one day post-irradiation and then began rebounding at four days post-irradiation. This rebound was slightly more robust in male mice compared to
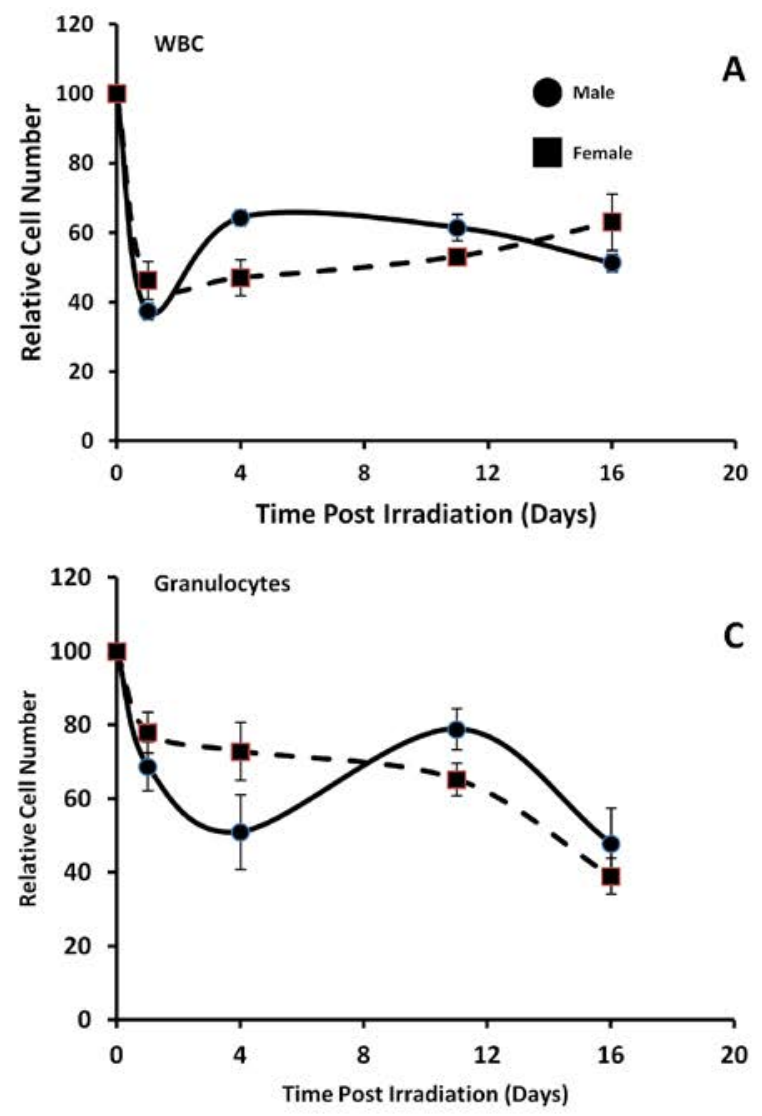

female mice. By day 16, WBC counts had recovered to ca. $50 \%$ of values in both male and female un-irradiated mice (Figure 1A and Figure 1B).
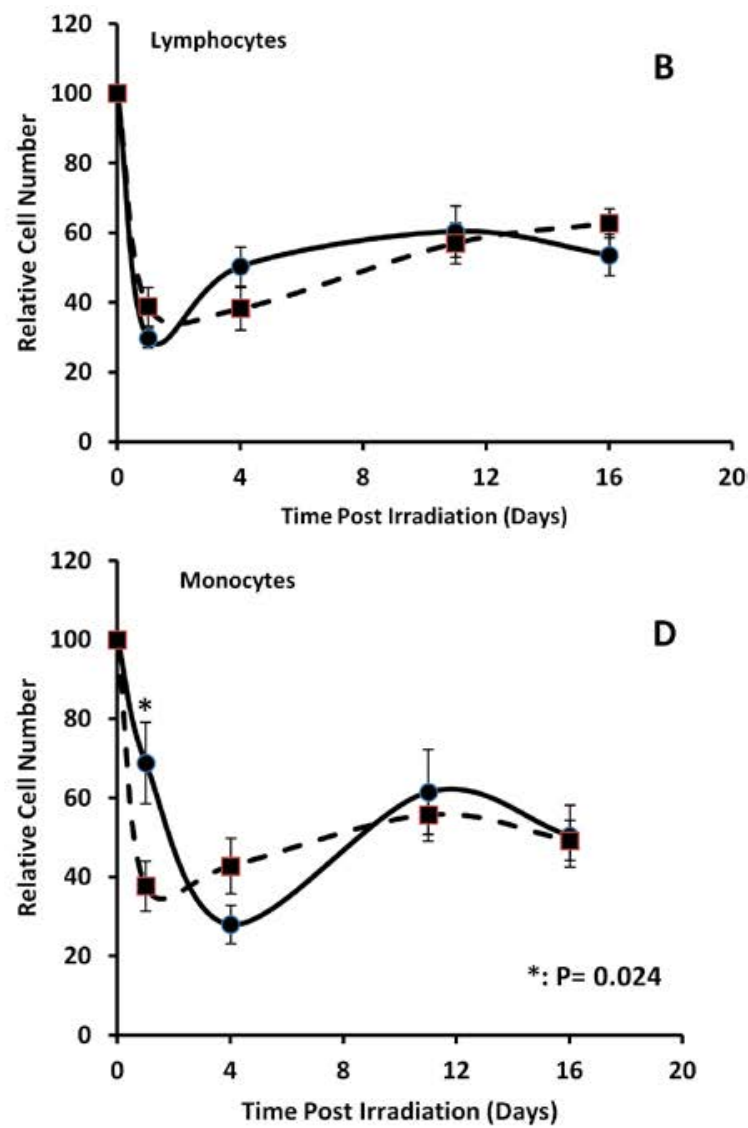

Figure 1. WBC (A), Lymphocytes (B), granulocytes (C) and monocytes (D) in male (•) and female (-) mice at $0,1,4,11$, and 16 days following treatment with $2 \mathrm{~Gy}$ gamma radiation. Results are presented as mean $\pm \mathrm{SE}$ of relative cell number (percent of control). Note that the decline in monocytes at 1 day post-irradiation was greater in females, compared with male mice $(\mathrm{P}=\mathbf{0 . 0 2 4})$.

In male mice, the granulocytes declined at day four, showed a moderate increase at day 11 postirradiation, and then declined again on day 16 post-irradiation in both male and female mice (Figure 1C). Monocytes declined at day one and then proceeded to rebound on days 11 and 16 post-irradiation. The decline in monocyte counts on day one post-irradiation was more pronounced in female vs. male mice $(60 \%$ vs. $30 \%$, respectively; $p=0.024)$, while the counts at later time points were not significantly different (Figure 1D).
The most prominent differences we observed in the course of these experiments were in platelets. In unirradiated female mice, platelet counts were $13 \%$ less than those in their male counterparts (see Table 1). Following the radiation exposures, platelets began declining at day four, reached a nadir at days 11-12, and then began to rebound. Male mice exhibited a higher rebound in platelet numbers compared with female mice. This effect was observed at a radiation dose of $1 \mathrm{~Gy}$ and was more pronounced at 2 Gy (Figure 2 and Table 2). 
Table 2. Platelet counts in mice following radiation exposure.

\begin{tabular}{|c|c|c|c|c|c|}
\hline Gender & Dose (Gy) & Time Post-IR & AVE & SD & n \\
\hline Male & 0 & 1 & 1108 & 322 & 11 \\
\hline Female & 0 & 1 & 1020 & 228 & 10 \\
\hline Male & 0.5 & 1 & 1082 & 151 & 10 \\
\hline Female & 0.5 & 1 & 1094 & 98 & 10 \\
\hline Male & 1 & 1 & 1091 & 192 & 9 \\
\hline Female & 1 & 1 & 1011 & 75 & 9 \\
\hline Male & 2 & 1 & 1123 & 110 & 8 \\
\hline Female & 2 & 1 & 1007 & 158 & 10 \\
\hline Male & 0 & 4 & 1061 & 204 & 11 \\
\hline Female & 0 & 4 & 905 & 224 & 11 \\
\hline Male & 0.5 & 4 & 1000 & 217 & 10 \\
\hline Female & 0.5 & 4 & 1092 & 207 & 9 \\
\hline Male & 1 & 4 & 1030 & 204 & 10 \\
\hline Female & 1 & 4 & 1088 & 240 & 8 \\
\hline Male & 2 & 4 & 1072 & 198 & 10 \\
\hline Female & 2 & 4 & 1034 & 99 & 10 \\
\hline Male & 0 & 11 & 1096 & 212 & 10 \\
\hline Female & 0 & 11 & 962 & 204 & 10 \\
\hline Male & 0.5 & 11 & 685 & 279 & 10 \\
\hline Female & 0.5 & 11 & 780 & 141 & 9 \\
\hline Male & 1 & 11 & 418 & 133 & 9 \\
\hline Female & 1 & 11 & 385 & 72 & 9 \\
\hline Male & 2 & 11 & 334 & 105 & 8 \\
\hline Female & 2 & 11 & 248 & 61 & 10 \\
\hline Male & 0 & 16 & 1116 & 245 & 10 \\
\hline Female & 0 & 16 & 1028 & 65 & 9 \\
\hline Male & 0.5 & 16 & 1185 & 101 & 5 \\
\hline Female & 0.5 & 16 & 1016 & 57 & 9 \\
\hline Male & 1 & 16 & 1163 & 102 & 10 \\
\hline Female & 1 & 16 & 834 & 95 & 10 \\
\hline Male & 2 & 16 & 871 & 154 & 10 \\
\hline Female & 2 & 16 & 470 & 159 & 9 \\
\hline
\end{tabular}



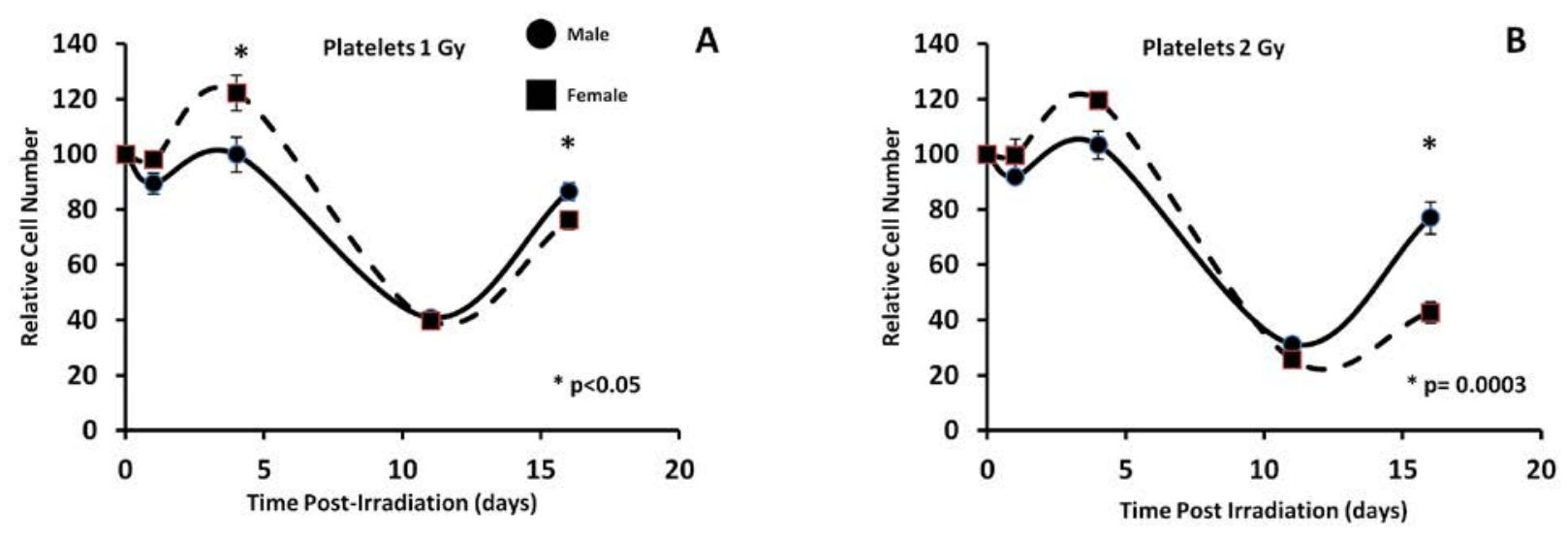

Figure 2. Platelet counts in male ( $\bullet$ ) and female (-) mice at $0,1,4,11$, and 16 days following treatment with 1 Gy (A) or 2 Gy gamma radiation (B). Results are presented as mean \pm SE of Relative Cell Number (percent of control). Note that platelet counts rebound faster in male mice on day 16, compared with female mice.

Previous reports have shown significant differences in RBC counts, hemoglobin, hematocrit, mean corpuscular volume, and platelet counts between different strains of mice (WirthDzięciołowska et al., 2009). In addition, both age and sex have an influence on the systemic immune responses following traumatic injury and hemorrhagic shock in $\mathrm{C} 3 \mathrm{H} / \mathrm{HeN}$ mice (Schneider et al., 2007). Some of these differences are thought to be a consequence of hormonal differences between male and females. Male $\mathrm{C} 3 \mathrm{H} / \mathrm{HeN}$ mice have been reported to have "somewhat" higher proportions of $32 \mathrm{~N}$ and $64 \mathrm{~N}$ megakaryocytes compared with females (Jackson et al., 1990). Washed platelets from C57BL/6J female mice were more sensitive to thrombin stimulation compared with their male counterparts. Thus, hematopoietic parameters are influenced by gender, as well as genetic (strain) background.

In conclusion, exposure to ionizing radiation has similar deleterious effects on the blood cells of male and female mice. The one major difference noted in the current study was the effect of radiation on platelets. At day 16 following a 2 Gy radiation exposure, platelet levels were $77 \%$ of unirradiated values in male mice, while in females they were $43 \%$. Interestingly, platelets obtained from female rats were reported to be more sensitive to the effects of terahertz band frequencies of $150 \mathrm{GHz}$ compared to male rats (Kirichuck et al., 2008) and are more sensitive to agonists compared with males (Leng et al., 2004).

Platelets are a rich source of cytokines and growth factors, such as platelet derived growth factor (PDGF), and they play an essential role in blood clotting and wound healing (Semple et al., 2011). Thus, it is conceivable that a reduction in platelet numbers could affect these biological processes.

\section{ACKNOWLEDGEMENTS}

This work was supported by the National Space Biomedical Research Institute (NSBRI)Center of Acute Radiation Research (CARR) grant and the NIH Radiation Biology Training Grant, 2T32CA009677. The NSBRI is funded through NASA NCC 9-58.

\section{REFERENCES}

Dainiak N (2002) Hematologic consequences of exposure to ionizing radiation. Experimental Hematology 30: 513-528

Gaberman E, Pinzur L, Levdansky L, Tsirlin M, Netzer N, Aberman Z, Gorodetsky R (2013) Mitigation of lethal radiation syndrome in mice by intramuscular injection of $3 \mathrm{D}$ cultured adherent human placental stromal cells. PloS One 8: e66549

Ghosh SP, Kulkarni S, Perkins MW, Hieber K, Pessu RL, Gambles K, Maniar M, Kao TC, Seed TM, Kumar KS (2012) Amelioration of 
radiation-induced hematopoietic and gastrointestinal damage by Ex-RAD ${ }^{\circledR}$ in mice. Journal of Radiation Research 53: 526-536

$\mathrm{Hu}$ S, Kim MH, McClellan GE, Cucinotta FA (2009) Modeling the acute health effects of astronauts from exposure to large solar particle events. Health Physics 96: 465-476

Jackson CW, Steward SA, Chenaille PJ, Ashmun RA, McDonald TP (1990) An analysis of megakaryocytopoiesis in the $\mathrm{C} 3 \mathrm{H}$ mouse: an animal model whose megakaryocytes have $32 \mathrm{~N}$ as the modal DNA class. Blood 76: 690696

Kerr RA (2013) Radiation will make astronauts' trip to Mars even riskier. Science 340: 1031

Kirichuck VF, Ivanov AN, Antipova ON, Krenickiy AP, Mayborodin AV, Tupikin VD (2008) Sex-specific differences in changes of disturbed functional activity of platelets in albino rats under the effect of terahertz electromagnetic radiation at nitric oxide frequencies. Bulletin of Experimental Biology and Medicine 145: 75-77

Leng XH, Hong SY, Larrucea S, Zhang W, Li TT, López JA, Bray PF (2004) Platelets of female mice are intrinsically more sensitive to agonists than are platelets of males. Arteriosclerosis, Thrombosis, and Vascular Biology 24: 376-381

Maks CJ, Wan XS, Ware JH, Romero-Weaver AL, Sanzari JK, Wilson J, Rightnar, S, Wroe AJ, Koss P, Gridley DS, Slater JM, Kennedy AR (2011) Analysis of white blood cell counts in mice after gamma- or protonradiation exposure. Radiation Research 176: 170-176

Romero-Weaver AL, Kennedy AR (2012) Comparison of two methods for the determination of the effects of ionizing radiation on blood cell counts in mice. International Journal of Biomedical Science 8: $7-15$

Romero-Weaver AL, Wan XS, Diffenderfer ES, Lin L, Kennedy AR (2013a) Effect of SPElike proton or photon radiation on the kinetics of mouse peripheral blood cells and radiation biological effectiveness determinations. Astrobiology 13: 570-577

Romero-Weaver AL, Wan XS, Diffenderfer ES, Lin L, Kennedy AR (2013b) Kinetics of neutrophils in mice exposed to radiation and/or granulocyte colony stimulating factor treatment. Radiation Research 180: 177-188

Sanzari JK, Cengel KA, Wan XS, Rusek A, Diffenderfer ES, Kennedy AR (2014) Acute hematological effects in mice exposed to the expected doses, dose-rates, and energies of solar particle event-like proton radiation. Life Sciences in Space Research 2: 86-91

Schneider CP, Schwacha MG, Chaudry IH (2007) Impact of sex and age on bone marrow immune responses in a murine model of trauma-hemorrhage. Journal of Applied Physiology 102: 113-121

Semple JW, Italiano JE, Freedman J (2011) Platelets and the immune continuum. Nature Reviews Immunology 11: 264-274

Smart DF, Shea MA (2003) The local time dependence of the anisotropic solar cosmic ray flux. Advances in Space Research 32(1): 109-114

Townsend LW (2005) Implications of the space radiation environment for human exploration in deep space. Radiation Protection Dosimetry 115(1-4): 44-50

Wilson JW, Cucinotta FA, Tai J, Simonsen LC, Shinn JL, Thibeault SA, Kim MY (1977) Galactic and solar cosmic ray shielding in deep space. NASA Technical Paper $\mathbf{3 6 8 2}$

Wirth-Dzięciołowska E, Karaszewska J, Pyśniak K, Smolińska M, Gajewska M (2009) Selected peripheral blood cell parameters in twelve inbred strains of laboratory mice. Animal Science Papers and Reports 27: 69-77

Zeitlin C, Hassler DM, Cucinotta FA, Ehresmann $\mathrm{B}$, Wimmer-Schweingruber RF, Brinza DE, Kang S, Weigle G, Böttcher S, Böhm E, Burmeister S, Guo J, Köhler J, Martin C, Posner A, Rafkin S, Reitz G (2013) Measurements of energetic particle radiation in transit to Mars on the Mars Science Laboratory. Science 340: 1080-1084 